\title{
Medical merchants: conflict of interest, office product sales and notifiable conduct
}

\author{
Malcolm H Parker, Jon L Wardle, Michael Weir and Cameron L Stewart
}

$\mathrm{O}$ ver 700 years ago, the Spanish theologian Ramon Llull (c. 1232-1316), in a chapter of his Libre de contemplació en Déu entitled "How we ought to be wary of what doctors do", observed that

they prescribe syrups and electuaries and other things for the sick because they share in the profits that the apothecaries make on what they sell to their patients. ${ }^{1}$

While medieval doctors received kickbacks from the apothecaries, many present-day doctors and patients will know (or know of) doctors who profit from selling "therapeutic" products to patients from their offices, although we are not aware of any data detailing the extent of this practice. Conflicts of interest, including the issue of direct selling to patients, are not confined to the medical profession, nor is this example the only type of conflict of interest in medical practice, but we believe this particular emerging phenomenon affecting the medical profession warrants scrutiny.

Doctors' selling of products to patients may represent a significant potential conflict of interest that could sometimes constitute notifiable conduct under the Health Practitioner Regulation National Law (National Law) provisions. We consider that the practice has emerged into some prominence with the advent of "integrative" medicine, which integrates complementary medicine into mainstream medical practice, but we do not consider that unethical selling of products is confined to this emerging field. Nor do our arguments constitute an outright rejection of integrative or complementary medicine. We are aware that thousands of clinical trials and over 500 systematic reviews have demonstrated therapeutic benefits of complementary and alternative medicine (CAM) treatments. ${ }^{2}$ We believe that, like all treatments, CAM modalities must be used in an ethical and evidence-based manner.

\section{Prescribing and dispensing}

Separating the prescribing of therapeutic products from their dispensing and sale accords with the ethical principle of minimising the harmful effects of excessive power being concentrated in the hands of one person or group. In medical practice, failing to separate these functions may result in considerations of financial gain distorting objective judgements about what is in the best interests of patients.

There are legal limits to the conjoining of prescribing and dispensing functions in relation to prescription products in Australia. The National Health Act 1953 (Cwlth) only permits approved pharmacists to supply pharmaceutical benefits (except where no pharmacist is practising). In the past, state and territory pharmacy legislation forbade doctors from supplying drugs, although in the past 10 years, new laws have recognised that doctors may supply drugs in the "ordinary" or "lawful" course of their profession (Box 1). Most often, this takes the form of doctors providing free samples to patients.

\section{ABSTRACT}

- Professional ethical codes identify the issue of conflict of interest, which can distort doctors' objective judgements concerning the best interests of patients.

- Legal fiduciary duties may be owed by doctors to patients in situations of potential conflict of interest.

- Prescribing and dispensing functions have been largely legally separated to prevent conflicts of interest arising.

- The advent of integrative medicine has been accompanied by an apparent growth of in-house selling of therapeutic products.

- Medical merchandising constitutes a prima-facie conflict of interest and may amount to notifiable conduct under the Health Practitioner Regulation National Law provisions.

- We believe that doctors who sell therapeutic products should adhere to strict conditions to avoid significantly departing from accepted professional standards.

- Doctors who have a reasonable belief that a colleague is failing to comply with these conditions could consider notifying the Medical Board of Australia.

MJA 2011; 194: 34-37

Many CAM practitioners see the prescribing-dispensing link as central to the individuation of therapeutic intervention in their practice, ${ }^{3}$ and the apparent growth in "one-stop" diagnosisprescription-dispensing is likely to be a result of the development of integrative medicine. This linking of functions will be attractive to those general practitioners, and to a lesser extent specialists, who integrate CAM modalities with their orthodox practice, with a view to providing more individuated care. ${ }^{4}$ While CAM practitioners often provide extemporaneous preparations of medicines, integrative GPs are more likely to use pre-packaged products, which lend themselves to financially efficient selling. Furthermore, although integrative practitioners claim that their practice combines the best evidence-based orthodox and complementary treatments (ie, providing "whole person medical care by integrating

1 State and territory legislation permitting limited supply of medicines by doctors

- Medicines, Poisons and Therapeutic Goods Regulation 2008 (ACT), Schedule 1, Part 1.3

- Poisons and Therapeutic Goods Act 1966 (NSW), s. 36AA

- Health (Drugs and Poisons) Regulation 1996 (Qld), s. 58

- Controlled Substances Act 1984 (SA), s. 15

- Poisons Act 1971 (Tas), s. 26

- Drugs, Poisons and Controlled Substances Act 1981 (Vic), s. 13

- Poisons Act 1964 (WA), s. 23 
evidence-based complementary medicine into mainstream practice" ${ }^{n 5}$ ), the effective prevention of direct selling of prescription items means that products sold in-house will generally be less well researched.

We do not oppose outright the sale of products to patients, because adequate infrastructure is yet to be developed for patients to be able to routinely obtain acceptable-quality CAM treatments; indeed, many practitioners retain clinic sales to avoid problems with brand substitution. However, we believe such sales should be enacted in accordance with the principles we discuss here.

\section{Conflicts of interest, fiduciary obligations and professional ethical codes}

In law, conflicts of interest are regulated by the concept of fiduciary obligations. These arise in relationships of trust and confidence, where the fiduciary must act in the interests of the beneficiary. In the 1996 case of Breen $v$ Williams, ${ }^{6}$ the High Court found that the doctor-patient relationship will not automatically give rise to fiduciary duties, but that fiduciary obligations may be owed by doctors when they have an undisclosed financial interest that potentially conflicts with the doctor's duty to provide independent diagnosis, advice and treatment. We argue that doctors who sell products which they prescribe would be in breach of their fiduciary obligations if they did not gain the fully informed consent of the patient by disclosing the known benefits and risks of the product and the nature of their financial interests in it.

Conflicts of interest are prominently discussed in professional statements and codes of ethics and conduct. The Australasian Integrative Medical Association supports doctors selling CAM products at a "reasonable profit", but qualifies this in terms of ensuring that decisions are made on clinical grounds rather than on the basis of profit, and that adequate information is provided to patients, including declaration of financial interests in sales. ${ }^{7}$ The Code of ethics of the Australian Medical Association (AMA) requires doctors not to exploit patients for any reason; to report suspected unethical or unprofessional conduct by colleagues to the appropriate peer review body; to ensure that any announcement or advertisement directed to patients is demonstrably true; and to refrain from entering into contracts that may conflict with professional integrity, clinical independence or the primary obligation to the patient. ${ }^{8}$ The AMA's position statement on complementary medicine states that the profession should set standards for practitioners who wish to augment their practice with CAM therapies, ${ }^{9}$ and its position statement on medicines requires doctors to choose the most suitable medicines, use them safely and effectively, and fully inform patients of their relevant side effects and interactions. ${ }^{10}$

The AMA's position statement concerning doctors' relationships with the pharmaceutical industry notes that doctors with a financial interest in dispensing pharmaceuticals, or who offer their patients health care-related services or products outside the normal function of a doctor, are in a prima-facie position of conflict of interest. ${ }^{11}$ Doctors should not dispense pharmaceuticals and other items for material gain unless there is no reasonable alternative, and they should not knowingly invest in pharmaceutical manufacturing companies where knowledge about the success of the company might be seen to inappropriately influence the manner of their practice or their prescribing behaviour. The AMA also advises that doctors should not be affiliated with pharmaceutical manufac- turers if the nature of their affiliation influences their medical practice in an inappropriate fashion.

The AMA's position statement on direct-to-consumer advertising (DTCA) is also pertinent, because it states that informed patient choice depends on receiving reliable, balanced information, free from the influence of commercial considerations. ${ }^{12}$ Both DTCA and direct selling to patients potentially compromise such unbiased information. Therapeutic products marketed only to health professionals, listed in s. 42AA of the Therapeutic Goods Act 1989 (Cwlth), or labelled as "practitioner dispensing only" are not subject to the same advertising restrictions as those marketed to the public. It is therefore possible for advertisers to make false or exaggerated claims to doctors, who may then pass these on (unwittingly or not) to patients. Practitioners may not be aware of this distinction, and some companies could potentially fan the misconception that "practitioner dispensing only" means "higher quality".

Australian general practices are accredited against standards set by the Royal Australian College of General Practitioners. ${ }^{13}$ These include the principle that patients should know in advance whether required health care services will attract additional costs to those of the consultation, so they can make an informed decision about their own health care, and the principle of informed consent, particularly as it pertains to medicines and their safety. ${ }^{13}$ Until national registration supervened, state medical boards supported these principles. The New South Wales Medical Board pointed out that economic harm can result from expenditure on harmless but inefficacious treatment, and required doctors to declare any interest in patient treatment. ${ }^{14}$ The Medical Practitioners Board of Victoria declared directly that "Doctors must not gain financial advantage by selling alternative therapeutic substances directly to patients". ${ }^{15}$ The Medical Board of Queensland enjoined registrants not to sell or market unconventional medicines and to advise patients of any pecuniary interest in products. ${ }^{16}$ Both the NSW and Queensland boards also advised doctors to prevent financial interests from influencing their prescribing decisions.

National registration now provides a uniform approach. The Medical Board of Australia has adopted the Australian Medical Council's Good medical practice: a code of conduct for doctors in Australia, including explicit sections concerning conflicts of interest and financial transparency. ${ }^{17}$ Patients must be informed when any interest of the doctor could affect or be perceived to affect patient care. Doctors must declare any financial interest in products endorsed by or sold from their practice, and they must not make an unjustifiable profit thereby.

\section{Two notable cases}

There have been few cases where conflicts of interest associated with selling products to patients have been legally tested. Nevertheless, two cases shed light on the issues.

In 1998, the New Zealand Health and Disability Commissioner found that a GP had breached a patient's rights by recommending that she purchase nutritional supplements at a cost of NZ\$200 per month, which the patient later discovered was part of a multilevel marketing scheme. ${ }^{18}$ The doctor failed to disclose his financial interest in each sale, indicate that the recommended treatment was an alternative modality, or indicate other options. The doctor was required to apologise to the patient and refund the cost of the supplements. He was further required to provide comprehensive 
information to consumers, including treatment options, their benefits and cost, and his pecuniary interest in any of them, as well as indicate whether he was acting as a GP or a nutritional specialist when making treatment recommendations.

In 2000, the Queensland Health Practitioners Tribunal suspended the registration of a medical practitioner on the grounds that he offered a dietary supplement manufactured by Mannatech consisting of a blend of monosaccharides, for which there is no scientific evidence of therapeutic efficacy, to one patient for the treatment of haemochromatosis, to another for treatment of cancer, as a business opportunity to the second patient's daughter, to a third patient for treatment of infertility, and to a fourth patient with epilepsy as a replacement for anticonvulsant and tranquiliser therapy. ${ }^{19}$ He had already breached prior medical board conditions by recommending Mannatech products (valued at up to $\mathrm{A} \$ 250 \mathrm{per}$ month) to patients and failing to inform patients of the likely effectiveness of the therapy.

The latter case is somewhat extreme, but the tribunal's judgment included observations that are pertinent to conflicts of interest in all situations:

- enthusiasm for certain products can cloud clinical judgement concerning the evidence for what is in a patient's best interests;

- acting in patients' best interests is one of the fundamental values of the profession;

- doctors must fully inform patients about new or unorthodox treatments;

- patients can be easily deceived into believing that they are receiving tested, efficacious treatments when this is not the case; and

- doctors should not make secret profits from supplying medications and devices. ${ }^{19}$

These cases are illustrative and do not constitute evidence for the frequency or general level of impropriety associated with cases of doctors selling therapeutic products. We contend, however, that there is anecdotal evidence of this kind of practice, with potential conflicts of interest and associated patient harm. In Box 2, we summarise the range of unacceptable practices arising in relation to direct product sales.

\section{Notifiable conduct and mandatory reporting}

The National Law provides for mandatory notification by registered health practitioners of notifiable conduct of colleagues, including

plac[ing] the public at risk of harm because the practitioner has practised the profession in a way that constitutes a significant departure from accepted professional standards. (Health Practitioner Regulation National Law Act 2009 [Qld] s. 140 [d])

The Medical Board of Australia's Guidelines for mandatory notifications further state that:

- the departure must be significant (ie, important or of consequence), serious and obvious to any reasonable practitioner;

- professional standards cover not only clinical skills, but also other standards of professional behaviour; and

- the risk of harm does not need to be a substantial risk, as long as the practitioner's practice involves a significant departure from accepted professional standards. ${ }^{21}$
2 Examples of unacceptable practice relating to direct therapeutic product sales by doctors

- Recommending expensive and minimally efficacious products ${ }^{\star 19}$

- Causing economic harm to patients ${ }^{18}$

- Failing to disclose financial interest in sales, mark-ups, or conflict of interest ${ }^{\star 19,20}$

- Enlisting or attempting to enlist patients as distributors, sellers or agents of products that the doctor distributes or sells ${ }^{19,20}$

- Failing to provide information regarding ongoing costs and alternative sources of products ${ }^{\star 18}$

- Failing to indicate other treatment options to the product offered for direct sale ${ }^{* 18}$

- Failing to inform patients accurately of the likely therapeutic effectiveness and risks of products ${ }^{* 18,19}$

- Failing to inform patients of the status of products as unorthodox and/or untested, if applicable ${ }^{\star 18-20}$

- Failing to use treatments appropriate to the condition being treated ${ }^{* 19}$

- Failing to appropriately document such discussions with patients and patient consent for these treatments ${ }^{18-20}$

* We are personally aware of further individual cases that have not been involved in legal or disciplinary proceedings but that have included examples of these types of behaviour.

\section{Doctors' obligations}

In our view, direct medical merchandising constitutes a prima-facie unacceptable conflict of interest, and in some cases may amount to notifiable conduct under the National Law, for the following reasons.

As noted, a range of professional ethical guidelines has existed for many years that require doctors to act in the best interests of and avoid exploiting patients; to inform them fully of the risks and benefits of treatment, including CAM therapies, free of commercial influence; to inform them of costs beyond the consultation, including treatment costs; to disclose financial interests; to avoid conflicts of interest, including those arising from financial interests in dispensing pharmaceuticals; to avoid economically harming patients by recommending inefficacious treatments; to avoid making unjustifiable profits; and to report unprofessional conduct of colleagues to the appropriate peer review body. As this article was being prepared, the AMA released a new position statement on medical professionalism and an updated statement on doctors' relationships with industry. ${ }^{22,23}$ Both statements warn of the potential risks to patient welfare from conflicts of interest.

Second, disciplinary bodies have prosecuted doctors' departures from accepted ethical and clinical standards involving commercial exploitation of patients through recommending products without adequate disclosure of efficacy and related financial interests.

Third, the National Law implies that circumstances justifying a mandatory notification might arise for sales of products by doctors, as this may constitute a departure from accepted professional standards if proper precautions are not followed to ensure ethical standards are met.

We suggest that, to provide for adequately informed consent, prevent harm and maximise patient benefit, and avoid notifiable conduct under the National Law, doctors who sell therapeutic products from their clinics or have other pecuniary interests 
relating to prescribed products should satisfy the following conditions:

- Provide full information to the patient about:

the evidence that the prescribed product is appropriate for the condition being treated;

the evidence for the risks and benefits of the product;

$>$ the ongoing cost to the patient of using the product;

$>$ any financial interest the doctor has in relation to the product; and

$>$ any mark-up on costs related to the product, which should ideally be no more than to render the transaction costneutral to the doctor.

- Offer the patient purchasing options by providing information on alternative methods of sourcing the product in question.

- Maintain accurate clinical records for products purchased by each patient, including the type and amount of each substance, its delivery method and the period of treatment.

We believe that doctors who sell products from their offices but do not comply with these conditions are arguably in serious breach of their ethical and professional obligations, and should be reported to their registration bodies. The further interesting (and, for some, disturbing) implication of national registration is that these doctors may now be legitimate subjects of the mandatory reporting obligation of any health professional colleague who is aware of their behaviour. Conversely, health professionals with a reasonable belief that a doctor they know or know of has failed to comply with these conditions could consider reporting him or her to the Medical Board of Australia, or potentially be at risk of unprofessional conduct themselves if they do not do so.

\section{Competing interests}

None identified.

\section{Author details}

Malcolm H Parker, MB BS, MLitt, MD, Associate Professor of Medical Ethics ${ }^{1}$

Jon L Wardle, BHSc(Nat), MPH, Public Health Research Scholar ${ }^{2}$

Michael Weir, BA, LLM, PhD, Professor and Associate Dean (Research) ${ }^{3}$

Cameron L Stewart, BEc, LLB(Hons), PhD, Associate Professor and

Director ${ }^{4}$

1 School of Medicine, University of Queensland, Brisbane, QLD.

2 School of Population Health, University of Queensland, Brisbane, QLD.

3 Faculty of Law, Bond University, Gold Coast, QLD.

4 Centre for Health Governance, Law and Ethics, University of Sydney, Sydney, NSW.

Correspondence: m.parker@uq.edu.au

\section{References}

1 Llull R. [Libre de contemplació en Déu Vol. II Cap. 115. Com hom se pren guarda de so que fan los metges] [Catalan]. 76-82. http:// orbita.bib.ub.es/ramon/bo.asp (accessed Mar 2010).

2 Ernst E, Pittler MH, B, Wider B. The desktop guide to complementary and alternative medicine: an evidence-based approach. 2nd ed. Edinburgh: Elsevier Mosby, 2006.
3 Lin $\mathrm{V}$, Bensoussan $\mathrm{A}$, Myers $\mathrm{SP}$, et al. The practice and regulatory requirements of naturopathy and Western herbal medicine. Melbourne: School of Public Health, La Trobe University, 2005.

4 Kotsirilos V. GPs' attitudes toward complementary medicine. Aust Fam Physician 2007; 36: 270-271.

5 Australasian Integrative Medicine Association. Mission statement. http:// www.aima.net.au/about_aima.html (accessed Aug 2010).

6 Breen v Williams (1996) 186 CLR 71.

7 Australasian Integrative Medicine Association. Position statement on sale of complementary medicines by medical practitioners. http:// www.aima.net.au/docs/aima_sale_of_cm_position_paper_2006.pdf (accessed Aug 2010).

8 Australian Medical Association. Code of ethics 2004. Editorially revised 2006 (ss. 1.1.h, 2.1.d, 2.2.b, 3.c). http://www.ama.com.au/codeofethics (accessed Mar 2010).

9 Australian Medical Association. AMA position statement on complementary medicine 2002 (s. 1.4). http://www.ama.com.au/node/2214 (accessed Mar 2010)

10 Australian Medical Association. AMA position statement on medicines 2008 (s. 2.1). http://www.ama.com.au/node/3332 (accessed Mar 2010).

11 Australian Medical Association. AMA position statement on doctors' relationships with the pharmaceutical industry 1994; revised 2002. http:// www.ama.com.au/node/1061 (accessed Mar 2010).

12 Australian Medical Association. AMA position statement on direct-toconsumer advertising 2007 (s. 1.1). http://www.ama.com.au/node/2931 (accessed Mar 2010).

13 Royal Australian College of General Practitioners. RACGP standards for general practices. 4th ed. Melbourne: RACGP, 2010. (Criteria 1.2.2 and 1.2.4.) http://www.racgp.org.au/standards (accessed Nov 2010).

14 New South Wales Medical Board. Policy - complementary health care (December 2004). http://www.nswmb.org.au/index.pl?page $=58$ (accessed Mar 2010).

15 Medical Practitioners Board of Victoria. Alternative or complementary medicines [archived webpage]. http://web.archive.org/web/ 20070831011953/medicalboardvic.org.au/content. php?sec $=35$ (accessed Nov 2010).

16 Medical Board of Queensland. Unconventional medical practice. http:// web.archive.org/web/20080719142718/www.medicalboard.qld.gov.au/ pdfs/unconventional-medical-practice.pdf (accessed Nov 2010).

17 Medical Board of Australia. Good medical practice: a code of conduct for doctors in Australia. http://www.medicalboard.gov.au/Codes-andGuidelines.aspx (accessed Nov 2010).

18 Health and Disability Commissioner (NZ). Decision 97HDC9575. http:// www.hdc.org.nz/decisions--case-notes/commissioner\%27s-decisions/ 1998/97hdc9575 (accessed Mar 2010).

19 Medical Board of Queensland v Raddatz [2000] QHPT 001. http:// archive.sclqld.org.au/qjudgment/2000/QHPT00-001.pdf (accessed Mar 2010).

20 Professional Standards Committee, NSW Medical Board. Inquiry into a complaint in relation to Dr Yvonne Tambyrajah. Sydney: NSWMB, 2009. http://www.nswmb.org.au/resources/806 (accessed Oct 2010).

21 Medical Board of Australia. Guidelines for mandatory notifications. http:// www.medicalboard.gov.au/Codes-and-Guidelines.aspx (accessed Oct 2010).

22 Australian Medical Association. AMA position statement on medical professionalism 2010. http://www.ama.com.au/node/5424 (accessed May 2010).

23 Australian Medical Association. AMA position statement on doctors' relationships with industry 2010. http://www.ama.com.au/node/5421 (accessed May 2010).

(Received 7 Jun 2010, accepted 28 Oct 2010) 